\title{
Trimethoprim-selective electrodes with molecularly imprinted polymers acting as ionophores and potentiometric transduction on graphite solid-contact
}

\author{
Tânia S.C.R. Rebelo, Sofia A.A. Almeida, J. Rafaela L. Guerreiro, \\ M. Conceição B.S.M. Montenegro ${ }^{c}$, M. Goreti F. Sales
}

\author{
A B S T R A C T
}

This work proposes a new biomimetic sensor material for trimethoprim. It is prepared by means of radical polymerization, having trimethylolpropane trimethacrylate as cross-linker, benzoyl peroxide as radicalar iniciator, chloroform as porogenic solvent, and methacrylic acid and 2-vinyl pyridine as monomers. Different percentages of sensor in a range between 1 and 6\% were studied. Their behavior was compared to that obtained with ion-exchanger quaternary ammonium salt (additive tetrakis(p-chlorophenyl)borate or tetraphenylborate). The effect of an anionic additive in the sensing membrane was also tested.

Trimethoprim sensors with $1 \%$ of imprinted particles from methacrylic acid monomers showed the best response in terms of slope $(59.7 \mathrm{mV} /$ decade $)$ and detection limit $\left(4.01 \times 10^{-7} \mathrm{~mol} / \mathrm{L}\right)$. These electrodes displayed also a good selectivity towards nickel, manganese aluminium, ammonium, lead, potassium, sodium, iron, chromium, sulfadiazine, alanine, cysteine, tryptophan, valine and glycine. The sensors were not affected by $\mathrm{pH}$ changes from 2 to 6 . They were successfully applied to the analysis of water from aquaculture.

Keywords:

Trimethoprim

Potentiometry

Ion selective sensors

Molecularly imprinted polymers

Aquaculture water

\section{Introduction}

Aquaculture is the production of aquatic organisms, such as the farming of fish, mollusks, crustaceans, amphibians and cultivating aquatic plants for man's use [1]. Industrial aquaculture is a rapidly growing industry in many developed and developing countries. A significant growth of food fish production has been observed over the past decade, due to the prevention or elimination of fish diseases. The introduction of veterinary medicines such as antimicrobials in the food production area has been the main responsible for this scenario [2].

Every year large quantities of antibiotics are administered to both humans and animals to treat and prevent diseases and infections. Antibiotics are also widely used at sub-therapeutic levels to growthpromoting. Often a high percentage of these antibiotics is excreted from dosed animals without metabolism or excreted in conjugated forms that can be readily converted back to the parent compounds [3].
Antibiotics are regarded as "pseudopersistent" contaminants due to their continual input into the ecosystem.

Therefore, the occurrence of antibiotics in the environment has received considerable attention [4]. There is a growing interest about their presence, persistence and fate in the environment because low levels of antibiotics can favor the proliferation of antibiotic-resistant bacteria $[5,6]$. Antibiotic contaminants may disarray microbial ecology, increase the proliferation of antibiotic-resistant pathogens and pose threats to human health [3]. For food safety purposes, fish samples must be subject to rigorous and frequent controls that ensure that residues of antimicrobials are below the maximum legal levels [7].

Trimethoprim (TMP) belongs to the class of synthetic antibiotics and has the chemical structure presented in Fig. 1, which is used in human medicine and veterinary medicine. A thorough search in the literature revealed that liquid chromatography (HPLC) is the analytical method currently available to detect this antibiotic in water and wastewater. These liquid chromatographic methods (HPLC) are usually coupled to mass spectrometry (MS) [8], tandem mass spectrometry (MS/MS) [9], electrospray mass spectrometry (ESI-MS) [10] and electrospray tandem mass spectrometry (ESI-MS/ MS) [11] detection. They usually involve high cost and complex sample pre-treating procedures that could be used only for confirmation of positive screening responses.

Potentiometric sensors such as ion-selective electrodes (ISEs) may be used for screening a wide variety of organic and inorganic species. 
<smiles>[B]=C(C(=C)C(=O)O)c1ccccn1</smiles>

Fig. 1. Chemical structure of TMP (A), VPY (B) and MAA (C).

Their short response times also make ISEs appropriate devices for routine analytical control. ISEs offer high precision and rapidity, low cost of analysis and enhanced selectivity [12]. The overall procedure is typically simple because the measures are targeted to a particular element. Typically, the analysis is carried out over few milliliters of aqueous solvent, containing only the analyte and buffer/ionic strength adjuster. The analysis is also non-destructive, allowing subsequent reading(s) of other parameter(s).

The core of an ISE is its selective membrane. A potential difference is observed from the transfer of the ionized analyte across the interface between the sample and membrane phase. The electroactive material in the membrane phase plays an active role by selectively transferring the main ion across the interface between the two phases [13]. Increased potentiometric performance may be achieved by using ionophores capable of discriminating the main ion from co-existing ones in a high extent. This may be achieved by doping the membranes with molecularly imprinted polymers (MIPs).

MIPs are synthetic compounds mimicking the action of biomolecules $[14,15]$ but holding many advantages over natural receptors. They offer higher stability at extreme $\mathrm{pH}$ and temperature conditions, high mechanical strength, low cost, and reusability. These features have led to the development of several MIP applications, including chromatography [16-18] artificial antibodies [19-22], chemical sensors [23-25], and solid-phase extraction (SPE) [26-28]. Therefore, MIPs may be used advantageously as sensing materials of ionselective electrodes (ISEs) [29].

The present work describes new TMP MIP based ISEs (no previously reported ISEs for TMP were found). The polymeric sensor was synthesized with methacrylic acid (MAA) or 2-vinyl pyridine (VP) functional monomers, polymerized within the template molecule and cross-linked by trimethylolpropane trimethacrylate (TMPTMA). TMP molecules were attracted to the tailored-cavities by means of non-covalent bound, because fast and reversible binding are required; non-covalent binding leads to less oriented sites than those in covalent imprinting but still with similar selectivity and sensitivity [30]. The sensing materials were dispersed in a poly(vinyl chloride) (PVC) matrix, plasticized with o-nitrophenyl octyl ether (oNPOE). A negative control of non-imprinted polymer (NIP) was also prepared with the same formulation, but with no template. The response behavior of the corresponding ISEs was reported herein, further applying the devices to the analysis of water samples from aquaculture fish farms.

\section{Experimental procedure}

\subsection{Reagents and solutions}

De-ionized water (conductivity $<0.1 \mu \mathrm{S} / \mathrm{cm}$ ) was employed. All chemicals were of analytical grade and used without further purification. Potassium tetrakis(4-chlorophenyl)borate (TpClPB), oNPOE, MAA and VPY were purchased from Fluka. TMP, PVC of high molecular weight, TMP, TMA and methanol $(\mathrm{MeOH})$ were purchased from Sigma-Aldrich; chloroform and acetic acid from Merck; benzoyl peroxide (BPO), and tetrahydrofuran (THF) from Riedel-deHäen.

Stock solutions of TMP $1.0 \times 10^{-3} \mathrm{~mol} / \mathrm{L}$ were prepared in water. Less concentrated standards were prepared by suitable dilution with water. Buffer solutions were $0.01 \mathrm{~mol} / \mathrm{L}$ Hepes ( $\mathrm{pH}$ 5.8).

The effect of $\mathrm{pH}$ was studied by imputing $\mathrm{pH}$ variations on $200 \mathrm{~mL}$ of a TMP solution $1.0 \times 10^{-4} \mathrm{~mol} / \mathrm{L}$. The $\mathrm{pH}$ of this solution was altered by little additions of either concentrated sulphuric acid or saturated sodium hydroxide solution, freshly prepared.

Interference of other chemicals such as nickel nitrate $(0.020 \mathrm{mg} / \mathrm{L})$, potassium chloride $(0.050 \mathrm{mg} / \mathrm{L})$, sodium chloride $(200 \mathrm{mg} / \mathrm{L})$, chromium nitrate $(0.050 \mathrm{mg} / \mathrm{L})$, ammonium nitrate $(0.500 \mathrm{mg} / \mathrm{L})$, lead nitrate $(0.025 \mathrm{mg} / \mathrm{L})$, manganese chloride $(0.050 \mathrm{mg} / \mathrm{L})$, iron sulphate $(0.200 \mathrm{mg} / \mathrm{L})$ and aluminium nitrate $(0.200 \mathrm{mg} / \mathrm{L})$ was evaluated. Limiting concentrations in law were selected for this purpose. Sulfadiazine $(2723 \mathrm{mg} / \mathrm{L})$, alanine $(891 \mathrm{mg} / \mathrm{L})$, cysteine $(1756 \mathrm{mg} / \mathrm{L})$, tryptophan $(2042 \mathrm{mg} / \mathrm{L})$, valine $(1172 \mathrm{mg} / \mathrm{L})$ and glycine $(750 \mathrm{mg} / \mathrm{L})$ were also tested as interfering species, all at $1.0 \times 10^{-2} \mathrm{~mol} / \mathrm{L}$. All these solutions were prepared in buffer.

\subsection{Apparatus}

All potential measurements were made by a Crison $\mu \mathrm{pH} 2002$ decimilivoltammeter $( \pm 0.1 \mathrm{mV}$ sensitivity), at room temperature and under constant stirring (Crison micro ST 2038). The output signal in steady state evaluations was transferred to a commutation unit and reconnected to one of six ways out, enabling the simultaneous reading of six ISEs. The assembly of the potentiometric cell was as follows: conductive graphite | TMP selective membrane | buffered solution (Hepes buffer $1 \times 10^{-2} \mathrm{~mol} / \mathrm{L}$, pH 5.8) || electrolyte solution, $\mathrm{KCl} \mid \mathrm{AgCl}(\mathrm{s})$ | $\mathrm{Ag}$. The reference electrode was an Orion $\mathrm{Ag} / \mathrm{AgCl}$ double-junction (Orion 90-02-00). The indicator electrode was obtained by applying the selective membrane over a solid-contact made of graphite/epoxy resin, integrated in a conventional configuration electrode body [29].

The $\mathrm{pH}$ was measured by a Crison CWL/S7 combined glass electrode connected to a decimilivoltammeter Crison, pH meter, GLP 22.

\subsection{Procedures}

\subsubsection{Synthesis of host-tailored polymers}

MIPs were prepared by placing the template (TMP, $0.26 \mathrm{~g}$ ) in a glass tube (14.0 mm i.d) with the functional monomer (MAA or VPY, $0.35 \mathrm{~g}$ ), the cross-linker (TMPTMA, $4 \mathrm{~g}$ ) and the radical initiator (BPO, $0.096 \mathrm{~g}$ ). All these were dissolved in $3 \mathrm{~mL}$ of chloroform. The mixture was sonicated, degassed with nitrogen for $5 \mathrm{~min}$, and cured at $70^{\circ} \mathrm{C}$ for $30 \mathrm{~min}$. The corresponding NIPs were prepared in the same way but the template was excluded from the procedure.

The obtained solid was ground and sieved to particle sizes ranging 50 to $150 \mu \mathrm{m}$. Extraction of the template molecule and washout of non-reacted species was carried out with methanol/acetic acid (50:50, v/v). The absence of TMP in the washout solution of the MIP particles was confirmed by measuring the absorbance at $210 \mathrm{~nm}$; the particles were repeatedly washed until TMP was no longer detected in consecutive washouts. Before use, all polymers (MIP/MAA, NIP/MAA, MIP/VPY, and NIP/VPY) were dried at $60^{\circ} \mathrm{C}$ until constant weight.

\subsubsection{Preparation of potentiometric sensors}

The selective membranes were prepared by mixing the PVC, the plasticizer (oNPOE) and the sensing polymer. The amounts used in this preparation were listed in Table 1 . Some membranes were also added of TpClPB, acting as anionic additive. The mixture was stirred until the PVC was well moistened, and dispersed in $3.0 \mathrm{~mL}$ THF. These membranes were placed in conductive supports of conventional 
Table 1

Membrane composition of TMP sensors casted in $180 \mathrm{mg}$ of PVC and their potentiometric features in $1.0 \times 10^{-2} \mathrm{~mol} / \mathrm{L} \mathrm{Hepes} \mathrm{buffer,} \mathrm{pH} 5$.

\begin{tabular}{|c|c|c|c|c|c|c|c|c|c|c|c|c|c|}
\hline \multirow[t]{3}{*}{ ISE } & \multicolumn{8}{|c|}{ Membrane composition } & \multirow{3}{*}{$\begin{array}{l}\text { Slope } \\
\text { (mV/decade) }\end{array}$} & \multirow{3}{*}{$\begin{array}{l}\mathrm{R}^{2} \\
(\mathrm{n}=5)\end{array}$} & \multirow{3}{*}{$\begin{array}{l}\text { LOD } \\
(\mathrm{mol} / \mathrm{L})\end{array}$} & \multirow{3}{*}{$\begin{array}{l}\text { LLLR } \\
(\mathrm{mol} / \mathrm{L})\end{array}$} & \multirow{3}{*}{$\begin{array}{l}\sigma_{\mathrm{v}} \\
(\mathrm{mV})\end{array}$} \\
\hline & \multirow{2}{*}{$\begin{array}{l}\text { AI, active } \\
\text { ingredient }\end{array}$} & \multirow{2}{*}{$\begin{array}{l}\text { PS, } \\
\text { plasticizer }\end{array}$} & \multirow{2}{*}{$\begin{array}{l}\text { Ad, } \\
\text { additive }\end{array}$} & \multicolumn{4}{|c|}{$\%, \mathrm{w}$} & \multirow{2}{*}{$\begin{array}{l}\text { AI:PS:Ad } \\
(\mathrm{mg})\end{array}$} & & & & & \\
\hline & & & & $\mathrm{AI}$ & PS & Ad & PVC & & & & & & \\
\hline I & MIP/MAA & oNFOE & - & 1 & 66 & - & 33 & $6: 380: 0$ & $59.7 \pm 2.5$ & 0.995 & $3.0 \times 10^{-7}$ & $4.0 \times 10^{-7}$ & 1.91 \\
\hline II & MIP/MAA & $o$ NFOE & - & 4 & 64 & - & 32 & $23: 370: 0$ & $49.4 \pm 0.3$ & 0.991 & $1.8 \times 10^{-6}$ & $2.0 \times 10^{-6}$ & 1.56 \\
\hline III & MIP/MAA & $o$ NFOE & - & 6 & 63 & - & 31 & $45: 480: 0$ & $52.6 \pm 0.2$ & 0.994 & $1.8 \times 10^{-6}$ & $2.0 \times 10^{-6}$ & 0.07 \\
\hline IV & NIP/MAA & oNFOE & - & 4 & 64 & - & 32 & $23: 370: 0$ & - & - & - & - & - \\
\hline V & MIP/VPY & $o \mathrm{NFOE}$ & - & 1 & 66 & - & 33 & $6: 380: 0$ & $64.0 \pm 0.8$ & 0.997 & $7.1 \times 10^{-7}$ & $8.0 \times 10^{-7}$ & 0.49 \\
\hline VI & MIP/VPY & $o \mathrm{NFOE}$ & - & 4 & 64 & - & 32 & $23: 370: 0$ & $53.5 \pm 0.6$ & 0.993 & $1.6 \times 10^{-6}$ & $2.0 \times 10^{-6}$ & 1.34 \\
\hline VII & MIP/VPY & $o$ NFOE & - & 6 & 63 & - & 31 & $45: 480: 0$ & $50.9 \pm 0.6$ & 0.993 & $3.2 \times 10^{-6}$ & $4.0 \times 10^{-6}$ & 0.57 \\
\hline VIII & NIP/VPY & $o \mathrm{NFOE}$ & - & 4 & 64 & - & 32 & $23: 370: 0$ & - & - & - & - & - \\
\hline IX & MIP/MAA & $o N F O E$ & TpClPB & 3.9 & 64.0 & 0.6 & 31.5 & $22: 361: 2.9$ & $62.6 \pm 1.28$ & 0.999 & $2.1 \times 10^{-6}$ & $8.5 \times 10^{-6}$ & 0.49 \\
\hline $\mathrm{X}$ & MIP/MAA & $o$ NFOE & TpCIPB & 4.0 & 63.8 & 0.3 & 31.9 & $23: 365: 1.8$ & $64.9 \pm 0.31$ & 0.995 & $2.5 \times 10^{-6}$ & $4.0 \times 10^{-6}$ & 1.95 \\
\hline XI & MIP/VPY & oNFOE & TpCIPB & 4.0 & 64.0 & 0.6 & 31.4 & $22: 358: 3.4$ & $60.0 \pm 0.30$ & 0.993 & $3.1 \times 10^{-6}$ & $4.0 \times 10^{-6}$ & 1.17 \\
\hline XII & MIP/VPY & $o \mathrm{NFOE}$ & TpCIPB & 4.0 & 64.0 & 0.3 & 31.7 & $23: 366: 1.8$ & $58.8 \pm 0.77$ & 0.993 & $2.8 \times 10^{-6}$ & $4.0 \times 10^{-6}$ & 2.15 \\
\hline XIII & ТРВ & $o N F O E$ & - & 2 & 64 & - & 34 & $11: 370: 0$ & $52.5 \pm 1.3$ & 0.993 & $2.4 \times 10^{-6}$ & $2.7 \times 10^{-6}$ & 0.49 \\
\hline XIV & TPB & $o$ NFOE & - & 4 & 64 & - & 32 & $23: 380: 0$ & $59.2 \pm 0.3$ & 0.995 & $4.4 \times 10^{-6}$ & $5.5 \times 10^{-6}$ & 1.95 \\
\hline $\mathrm{XV}$ & TPB & $o \mathrm{NFOE}$ & - & 6 & 63 & - & 31 & $38: 400: 0$ & $88.1 \pm 0.3$ & 0.990 & $1.1 \times 10^{-6}$ & $2.0 \times 10^{-6}$ & 2.19 \\
\hline XVI & TPB & $o N F O E$ & - & 8 & 62 & - & 30 & $51: 400: 0$ & $99.7 \pm 0.8$ & 0.990 & $5.6 \times 10^{-6}$ & $7.0 \times 10^{-6}$ & 3.89 \\
\hline
\end{tabular}

shape. Membranes were let dry for $24 \mathrm{~h}$ and conditioned in a TMP solution, $1 \times 10^{-4} \mathrm{~mol} / \mathrm{L}$. The electrodes were kept in this solution when not in use.

\subsubsection{Potentiometric measures}

All potentiometric measurements were carried out at room temperature. Emf values of each electrode were measured in solutions with fixed $\mathrm{pH}$. Increasing concentration levels of TMP were obtained by transferring $0.020-5.0 \mathrm{~mL}$ aliquots of TMP $1.0 \times 10^{-3} \mathrm{~mol} / \mathrm{L}$ standard solution to a $100 \mathrm{~mL}$ beaker containing $50.0 \mathrm{~mL}$ of suitable buffer $1.0 \times 10^{-2} \mathrm{~mol} / \mathrm{L}$. Potential readings were recorded after stabilization to $\pm 0.2 \mathrm{mV}$ and emf was plotted as a function of logarithm TMP concentration. Calibration plots were used for subsequent determination of unknown TMP concentrations.

\subsubsection{Binding study}

About $15.0 \mathrm{mg}$ of washed and dried MIP particles were let stand in $8.00 \mathrm{~mL}$ of TMP standard solutions, ranging $0.100-1.00 \mathrm{mmol} / \mathrm{L}$ and prepared in Hepes buffer $1 \times 10^{-2} \mathrm{~mol} / \mathrm{L}$. The mixtures were oscillated for $24 \mathrm{~h}$ at room temperature and the solid-phase separated by centrifugation (3000 rpm, $10 \mathrm{~min}$ ). The concentration of free TMP in the supernatant was detected by UV spectrophotometry at $210 \mathrm{~nm}$, after previous spectrophotometric calibration. The amount of TMP bound to the polymer was calculated by subtracting the concentration of free TMP from the initial TMP concentration. The data obtained was used for Scatchard analysis.

\subsubsection{Determination of TMP in aquaculture water}

Emf measurements in steady state were made by immersing the electrochemical cell in the test solution and waiting until equilibrium was reached $(10-20 \mathrm{~s})$. Successive $0.050-0.150 \mathrm{~mL}$ aliquots of the standard TMP solutions were added for calibration. Water samples with TMP concentrations ranging from 1 to $4 \mathrm{mg} / \mathrm{L}$ were analyzed afterwards. Blank aquaculture waters from different fishfarms in sweet water were spiked for this purpose. The TMP concentration was calculated using previous calibration data.

\section{Results and discussions}

The molecular-level phenomenon sensed by an ISE is the binding between the ionophore and the target ion [31], thereby attributing the ionophore a key role in the sensitivity and the selectivity of the sensing device. Therefore, when MIP materials are used as ionophore, their strength and kind of binding to the analyte, TMP, should be associated to the general behavior of the corresponding ISEs.

\subsection{Binding characteristic of the MIP}

Adsorption isotherms plot the concentrations of TMP bound to the solid sorbent (MIP) in equilibrium versus free TMP. For this purpose, the MIP particles were let stand under continuous stirring with different concentrations of TMP, and free concentration of TMP in equilibrium was determined spectrophotometrically. The results obtained were plotted in Fig. 2. As expected, the results showed that the high TMP concentrations led to the saturation of binding sites. The resulting binding capacity of MIPs was calculated according to following equation:

$Q=\frac{\mu \operatorname{mol}(\text { TMPbound })}{g(\text { MIP })}=\frac{\left(C_{i}-C_{f}\right) \times V_{s} \times 1000}{M_{M I P}}$

where $\mathrm{Q}$ is binding capacity of MIPs $(\mu \mathrm{mol} / \mathrm{g}), \mathrm{C}_{\mathrm{i}}$ the initial TPM concentration $(\mu \mathrm{mol} / \mathrm{ml}), C_{\mathrm{f}}$ the final TPM concentration $(\mu \mathrm{mol} / \mathrm{ml})$, versus the volume of solution tested $(\mathrm{ml})$ and $\mathrm{M}_{\mathrm{MIP}}$ the mass of dried polymer ( $\mathrm{mg}$ ). Binding capacities were plotted against the initial TMP concentration (Fig. 2A). The adsorption data showed that the binding capacity of MAA or VPY MIP particles increased with the increasing of the initial concentration of TPM, reaching to saturation at higher concentrations.

The binding data were further processed with Scatchard analysis, providing important information on binding properties of the imprinted particles. The Scatchard equation,

$\mathrm{Q} / \mathrm{C}_{\text {free }}=\left(\mathrm{Q}_{\max }-\mathrm{Q}\right) / \mathrm{K}_{\mathrm{d}}$

was applied for this purpose, where $Q$ is the binding capacity; $C_{\text {free }}$ the free analytical concentration in equilibrium $(\mu \mathrm{mol} / \mathrm{L}) ; \mathrm{Q}_{\max }$ is the maximum apparent binding capacity; and $K_{d}$ is the dissociation constant in the binding site. The equilibrium dissociation constant was calculated from the slopes and the apparent maximum number of binding sites from the $y$-intercepts in the linear plot of $Q / C_{\text {free }}$ versus $Q$.

The Scatchard plot in Fig. 2B showed a linear behavior for MAA and VPY imprinted polymers, suggesting the existence of a specific binding to the imprinted cavities, probably resulting from hydrogen bridges. For MAA-based MIP, the apparent $\mathrm{K}_{\mathrm{d}}$ was $318 \mu \mathrm{mol} \mathrm{L}-1$, 
A

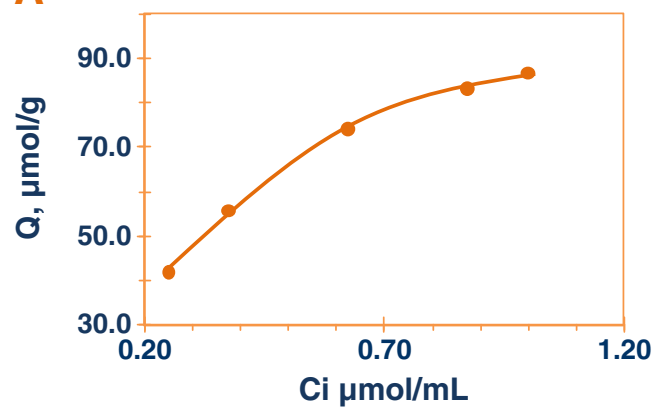

A

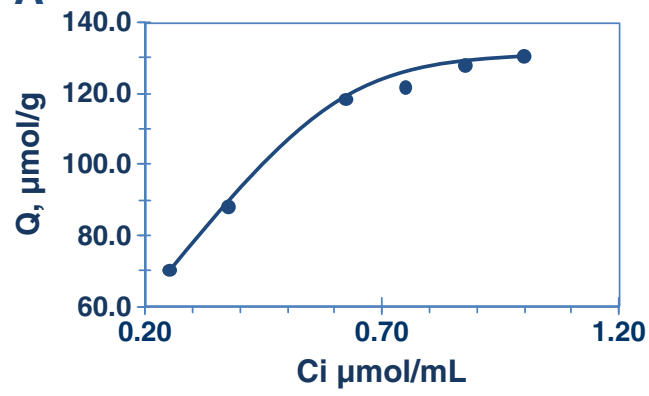

B

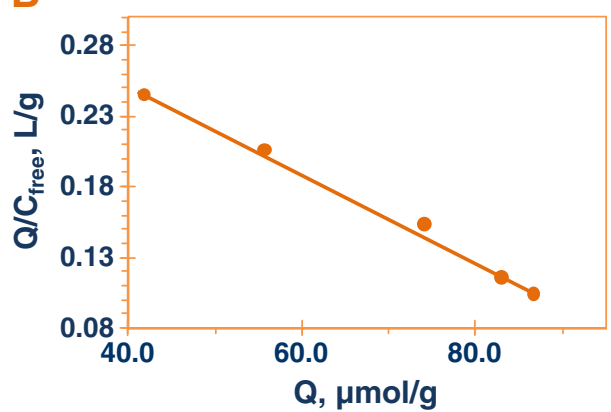

B

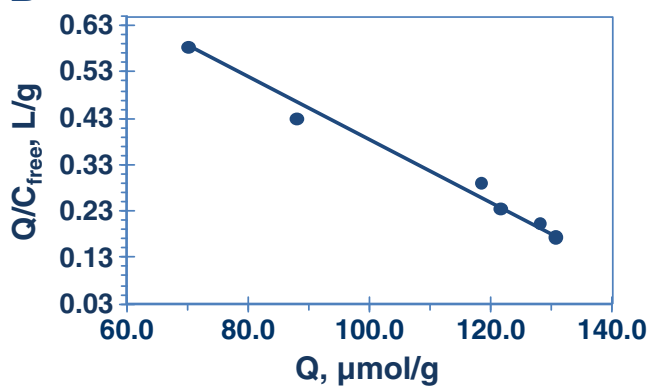

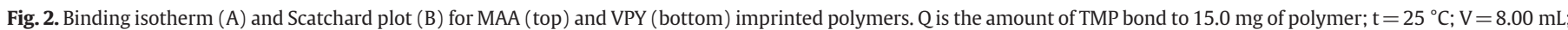
binding time: $24 \mathrm{~h}$.

associated with site populations of $10 \mu \mathrm{mol} / \mathrm{g}$ for dry polymer, while for VPY-based MIP the apparent $K_{d}$ was $683 \mu \mathrm{mol} / \mathrm{L}$, for site populations of $263 \mu \mathrm{mol} / \mathrm{g}$. Overall, the results pointed out a higher affinity of TMP for MIPs synthesized with MAA monomers.

\subsection{MIP/NIP as potentiometric ionophore}

TMP sensors were prepared with MIP or NIP particles, acting as electroactive materials dispersed in PVC plasticized with oNPOE. These particles were prepared from MAA (ISEs I to IV) or VPY (ISEs VI to VIII) monomers, and were added in different amounts. Characterization of the corresponding analytical features followed IUPAC recommendations [32], and was made under static mode of operation. The main results are presented in Table 1.

The amount of ionophore in the membrane was varied from 1 to $6 \%$ for both monomers. The MAA-based sensors (Fig. 3, left) with $4 \%$ and $6 \%$ of sensing material displayed average slopes of 49.4 and $52.6 \mathrm{mV} /$ decade, respectively, and a limit of detection of $1.8 \times 10^{-6} \mathrm{~mol} / \mathrm{L}$. The sensor with $1 \%$ sensing material showed a better potentiometric response, with Nernstian slopes of 59.7 and LOD of $3.0 \times 10^{-7} \mathrm{~mol} / \mathrm{L}$. The membranes with $4 \%$ and $6 \%$ of VPY-based ionophore (Fig. 3, right) presented similar behavior, with average slopes of 53.5 and $50.9 \mathrm{mV} /$ decade and LODs of $1.6 \times 10^{-6}$ and $3.2 \times 10^{-6} \mathrm{~mol} / \mathrm{L}$, respectively. As observed for MAA sensors, membranes with 1\% VPY-based ionophore displayed a better response, with a significant slope and LOD improvement, to $64 \mathrm{mV} /$ decade and $7.1 \times 10^{-7} \mathrm{~mol} / \mathrm{L}$, respectively. Overall, both MIP sensors with $1 \%$ of sensing material presented good analytical features, with particles from MAA monomers displaying the best potentiometric response.

The effect of the imprinting process in the polymeric matrix was established by comparing the response of TMP sensors prepared with either MIP or NIP particles. Overall, all sensors with MIP particles displayed a linear behavior against the logarithm concentration of TMP within a wide concentration range, while NIP showed almost steady emf (Fig. 3). These results suggested that TMP recognition was made solely on the tailored-cavities of each polymer. Furthermore, because the electrodes did not require an ionic additive, it seems that the ionophore was playing as a charged carrier.

\subsection{Effect of additive}

Typically, the addition of ionic compounds of lipophilic nature reduces anionic interference and lowers the electrical resistance of the membranes [33]. In this case, an anionic additive was used, with the purpose of lowering the limit of detection of the sensing units. TpClPB was employed for this purpose (ISEs IX-XII).

In general terms, a positive impact was observed in terms of slope, with all electrodes displaying Nernstian or near-Nernstian behavior. However, the main purpose of this study was not fulfilled because the lower limit of linear range and the limit of detection increased in comparison with the corresponding ISEs without additive (ISEs I and $\mathrm{V}$ in Table 1). This behavior was attributed to the additive, because electrodes prepared with 0.6 or $0.3 \%$ of additive (and without MIP) showed linear behavior after $4.0 \times 10^{-6} \mathrm{~mol} / \mathrm{L}$ and Nernstian slopes. These results corroborated with a charged carrier role for MIP particles. In general terms, the best responses were obtained from ISEs with no additive on the selective membrane, in particular those with $1 \%$ of MIP.

\subsection{Comparison with an ion-exchanger}

For comparison purposes, TMP selective electrodes were also prepared with a conventional ion-exchanger. TPB was selected and added in different amounts, lying in the range from 2 to $8 \%$ (ISEs XIII to XIV). Both 6 and $8 \%$ provided supra-Nernstian slopes, with 88.1 and $99.7 \mathrm{mV} /$ decade, respectively, while $2 \%$ presented sub-Nernstian slopes of $52.5 \mathrm{mV} /$ decade. The quantity of ionophore that provided the best response was $4 \%$, with a slope of $59.2 \mathrm{mV} /$ decade and LOD of $4.4 \times 10^{-6} \mathrm{~mol} / \mathrm{L}$. These results are shown in Fig.4.

Comparing the electrodes prepared with MIP or conventional ionexchanger, the best analytical response was produced by MIP sensors, providing the lowest LOD (lower in one decade), and the widest linear ranges. 

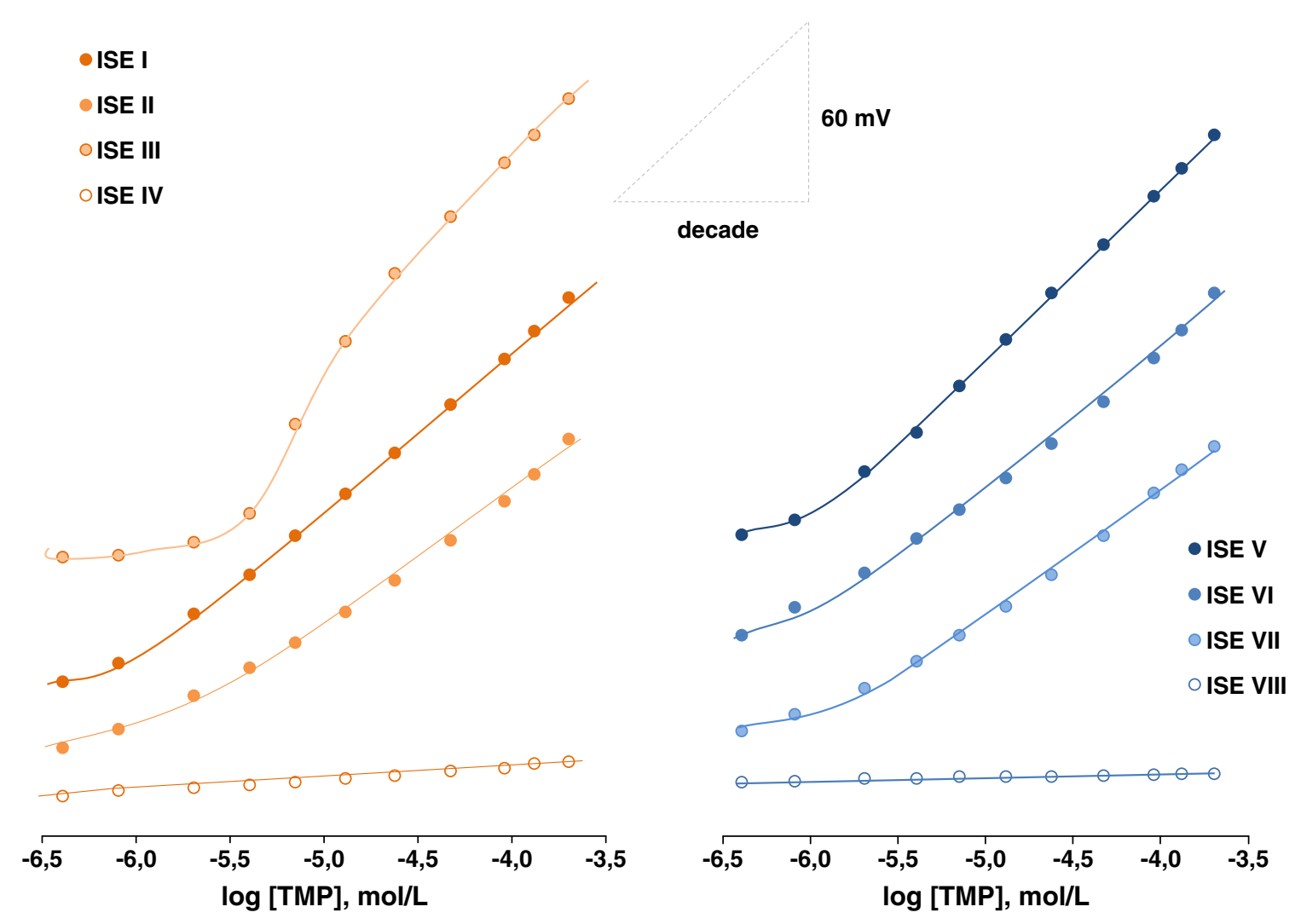

Fig. 3. Potentiometric response of MAA and VPY-based ISEs, with different percentages of molecularly (non)imprinted materials as ionophore (all data points of the calibration and not the linear ranges).
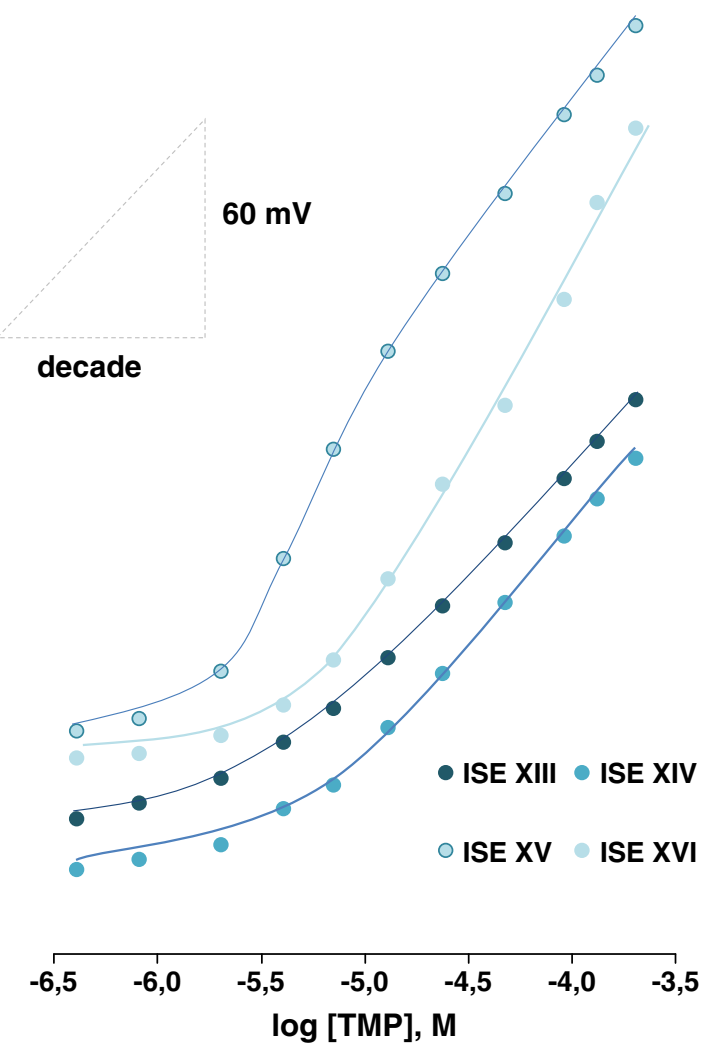

Fig. 4. Potentiometric response of TPB ISEs, with different percentages of ion-exchanger (all data points of the calibration and not the linear ranges).

\subsection{Response time and lifetime}

The time required to achieve a steady potential response $( \pm 3 \mathrm{mV})$ using the proposed sensors in $1.00 \times 10^{-3} \mathrm{~mol} / \mathrm{L} \mathrm{TMP}$ solutions with a rapid 10 -fold increase in concentration was $<15 \mathrm{~s}$. After several calibrations for each sensor, low potential drift, long-term stability and negligible change in sensors response were observed. The sensors were stored and conditioned in $1 \times 10^{-5} \mathrm{~mol} / \mathrm{L}$ TMP solution. With all sensors examined, the detection limits, response times, linear range and calibration slopes were reproducible within $\pm 3 \%$ of their original values over a period of at least 5 weeks.

\subsection{Effect of $p H$}

Given that the electrodes are sensing the cationic form of TMP, the $\mathrm{pH}$ must play an important role on the potentiometric response. The pKa of TMP is 6.6 , at $25^{\circ} \mathrm{C}$ [34], and, consequently, when the $\mathrm{pH}$ decreases from 6.6, the ratio of protonated/unprotonated species becomes higher.

Reilley diagrams were drawn for this study. They plot the emf against the $\mathrm{pH}$ of the measuring solution. The diagrams depicted in Fig. 5 were obtained by measuring the emf of a $1 \times 10^{-4} \mathrm{~mol} / \mathrm{L} \mathrm{TMP}$ solution, to which the pH was altered (from 1 to 11 ) by adding small amounts of saturated sodium hydroxide or concentrated hydrochloric acid solutions.

MAA or VPY-based sensors displayed similar behavior. Both sensors showed steady potentials from 2 to 6 , with emf variations of about $\pm 10 \mathrm{mV}$ (Fig. 5). The emf started decreasing for $\mathrm{pHs} \geq 6$. This was attributed to the increasing amount of the unionized form of TMP. A decrease in the emf was also observed for $\mathrm{pHs} \leq 2$, which could result from the double-charged TMP species. 


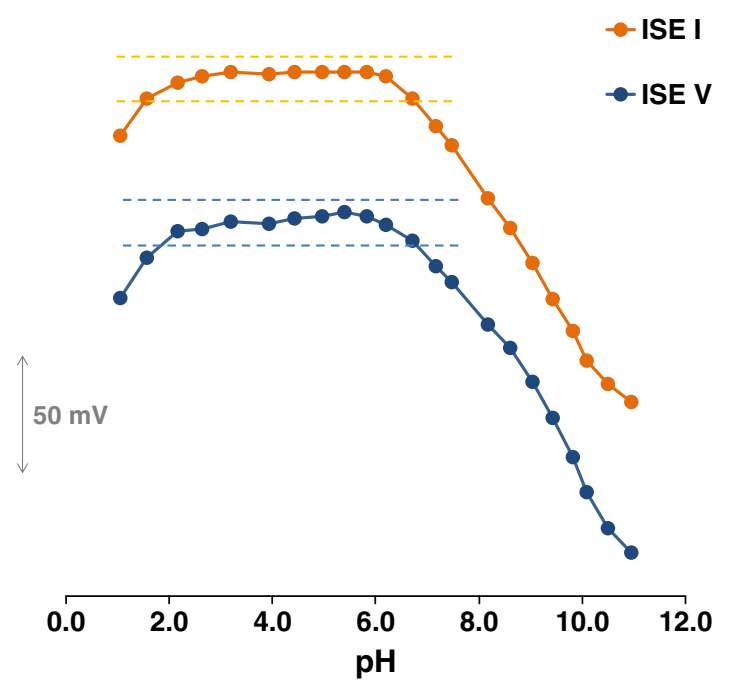

Fig. 5. Reilley diagram for MAA and VPY sensors.

\subsection{Sensor selectivity}

Selectivity of an ISE is generally governed by electrostatic and stereospecific aspects involving the interactions between ionophore/ ion-exchanger and the analyte in the membrane/solution interface, and is assessed by means of potentiometric selectivity coefficients $\left(\mathrm{K}^{\mathrm{POT}}\right)$. The values of $\log \mathrm{K}^{\mathrm{Pot}}$ quantify the interference of a certain compound: the more negative the values are, less interference they cause. Potentiometric selectivity coefficients can be measured with different methods that fall into one of two main groups: mixed solution methods (MSM) or separate solution methods (SSM) [32]. In this work, MSM were always employed, using both fixed interference method (FIM) and matched potential method (MPM) [35]. Their selectivity coefficients were calculated, respectively, after the following equations:

$K_{T M P, J}^{P O T}=a_{T M P} /\left(a_{J}\right)^{Z_{T M P} / Z_{J}}$

$K_{T M P, J}^{P O T}=\left(a_{T M P}^{\prime}-a_{T M P}\right) / a_{J}$

In Eq. (3), the $\mathrm{K}^{\mathrm{POT}}$ is the intersection of the extrapolated linear portions of the plot emf versus the logarithm of TMP concentration, $a_{T M P}$ and $a_{J}$ are the concentrations of main and interfering species and $Z_{T M P}$ and $Z_{J}$ are the ionic charges of main and interfering ions of the same sign, positive or negative. For Eq. (4) the reference solution containing a fixed activity received an adding of the primary ion solution whilst recording the change $(\Delta \mathrm{E})$. Afterwards the same procedure was carried out but an interfering ion was used instead of the primary ion solution. Once again the change in $(\Delta \mathrm{E})$ was recorded. The change in potential produced at the constant background of the primary ion must be the same in both cases.

The FIM was employed to assess the interference of cationic species whose control in water for human consumption is obligatory in the Portuguese law. These include nickel $\left(\mathrm{Ni}^{+}\right)$, potassium $\left(\mathrm{K}^{+}\right)$, sodium $\left(\mathrm{Na}^{+}\right)$, chromium $\left(\mathrm{Cr}^{3+}\right)$, ammonium $\left(\mathrm{NH}_{4}^{+}\right)$, lead $\left(\mathrm{Pb}^{2+}\right)$, manganese $\left(\mathrm{Mn}^{2+}\right)$, iron $\left(\mathrm{Fe}^{2+}\right)$ and aluminium $\left(\mathrm{Al}^{3+}\right)$. The concentration established for each species was the limiting value: 0.020 ; $0.050 ; 200.0 ; 0.050 ; 0.500 ; 0.025 ; 0.050 ; 0.200$; and $0.200 \mathrm{mg} / \mathrm{L}$, respectively. As may be seen in Fig. 6, both MAA and VPY-based sensors displayed very good selectivity $\left(-5.7<\log \mathrm{K}^{\mathrm{POT}}<-2.6\right)$. MIPs obtained from MAA monomers showed a slightly better selectivity, which is in agreement with the binding properties.

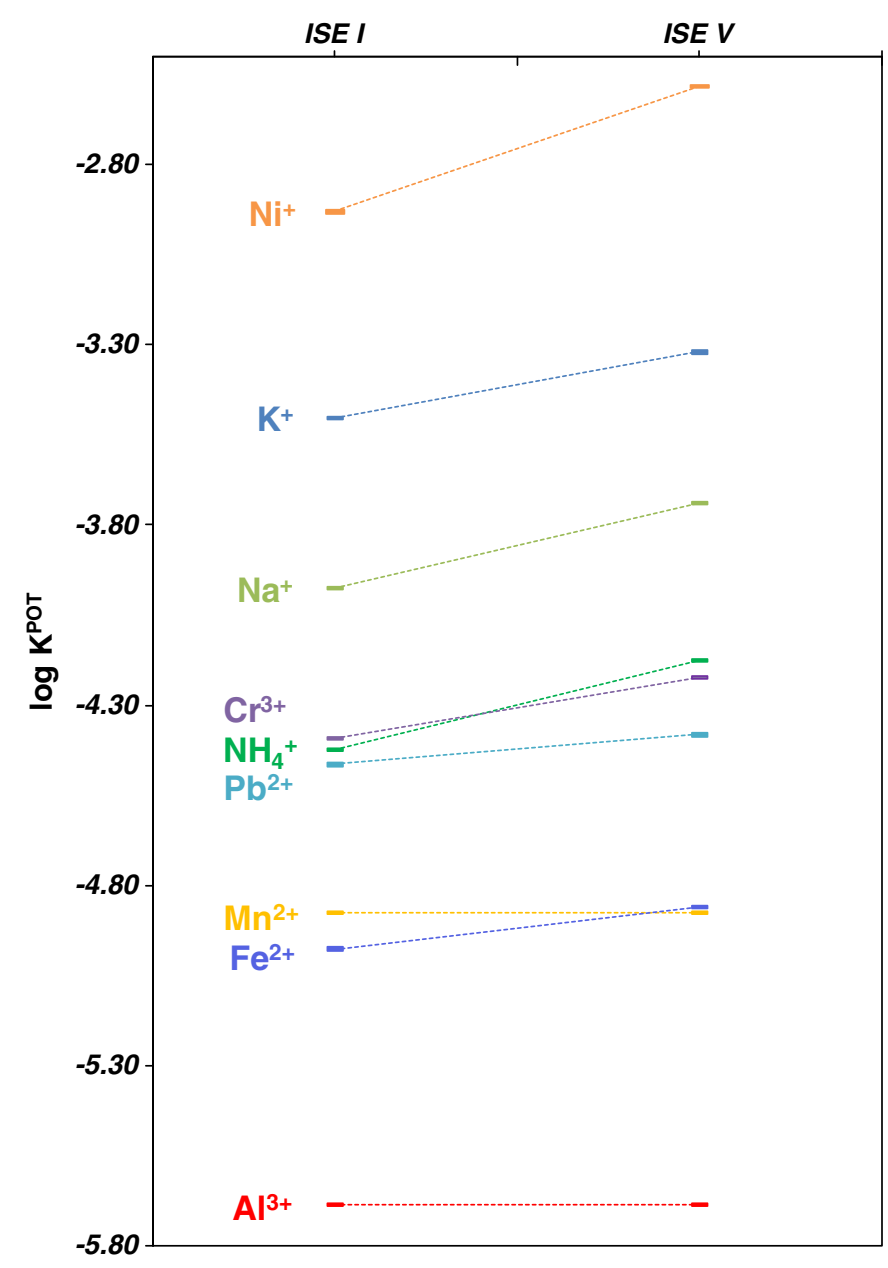

Fig. 6. Potentiometric selectivity coefficients $\left(\log K^{P O T}\right)$ of TMP membrane based sensors, in $1 \times 10^{-2} \mathrm{~mol} / \mathrm{L}$ Hepes buffer of $\mathrm{pH} 5.8$ by separate solution method.

The MPM was used for organic species that could be neutral, negatively charged or amphoteric. Sulfadiazine (SDZ) was included in this study because it is an antibiotic of common use in aquaculture, always associated to TMP for an increased therapeutic efficiency. Other organic compounds were alanine, cysteine, tryptophan, valine and glycine, aminoacids that may be included in fish-food. In general, it was not possible to estimate $\log \mathrm{K}^{\mathrm{POT}}$ because it the emf change was never achieved for TMP concentrations varying from $1.00 \times 10^{-5}$ to $1.00 \times 10^{-4} \mathrm{~mol} / \mathrm{L}$ (associated to a change of $50 \mathrm{mV}$ ).

Considering the previous results, tolerance levels were calculated instead of $\mathrm{K}^{\mathrm{POT}}$. The tolerance levels in Table 2 indicated that SDZ was the least interfering compound and that glycine was the one that had the higher interference. The relative order of tolerance levels for the proposed sensors was $\mathrm{SDZ}>$ tryptophan $>$ cysteine $>$ valine $>$ alanine $>$ glycine. In general, negligible interference was found from these compounds.

Table 2

Tolerance levels for several organic compounds producing an error below $\pm 1 \mathrm{mV}$.

\begin{tabular}{ll}
\hline Interfering & Tolerance level $(\mathrm{mg} / \mathrm{L})$ \\
\hline Sulfadiazine & $<2700$ \\
Tryptophan & $<2040$ \\
Cysteine & $<1750$ \\
Valine & $<1170$ \\
Alanine & $<900$ \\
Glycine & $<750$ \\
\hline
\end{tabular}




\subsection{Determination of TMP in aquaculture water}

The potentiometric method was applied to determine TMP in aquaculture water from several bream freshwater cultures. Blank samples were spiked and analyzed for concentrations ranging about 1.00 to $4.00 \mathrm{mg} / \mathrm{L}$. The analytical results confirmed the accuracy and precision of the present work (Tables 3 and 4). Recoveries ranged from 86 to 105\%, for sensors prepared with 1\% MAA MIP particles and 81-97\% for sensors prepared with 1\% VPY monomer, thus suggesting the accuracy of the analytical data. Relative standard deviations were also low, and confirmed the precision of the proposed method. Student $t$ test (at 95\% confidence level) was also applied and confirmed the accuracy of the analytical data because the $p$ values (Tables 3 and 4 ) were less than $t$ critical (3.18). The values of $p$ ranged from 0.01 to 0.77 .

The analytical results of MAA-based sensors seemed however better than those obtained with the VPY because the positive and negative recoveries suggest the absence of systematic bias. Overall, the MAA sensors were successfully applied to the analysis of water from aquaculture.

\section{Conclusions}

The technique of molecular imprinting polymerization was successfully applied to produce TMP sensors of potentiometric transduction. The MIP particles seemed to be working in a charged carrier mechanism. NIP-based sensors were unable to recognize the template and an additive was not required and undesired. Sensors with $1 \%$ of MIP particles offered good analytical performance. The main advantages of these sensors include the simplicity of design, low response time, high precision, high accuracy, low detection limits and good selectivity.

The selective membranes with $1 \%$ of MIP/MAA sensing material showed better analytical responses and were successfully applied to the analysis of aquaculture waters. This method is low cost expensive, allows the local routine analysis and is environmentally friendlier than the chromatographic technique, the only one in the literature devoted to the analysis of TPM in water. The limit of detection of chromatographic

Table 3

Potentiomeric determination of TMP in aquaculture water using MAA/MIP based membrane sensor.

\begin{tabular}{lllrrr}
\hline \multirow{2}{*}{ Sample } & $\begin{array}{l}\text { Concentration } \\
\text { TMP }(\mathrm{mg} / \mathrm{L})\end{array}$ & \multicolumn{2}{l}{ Found $(\mathrm{mg} / \mathrm{L})$} & ER $(\%)$ & $p$ tailed $^{*}$ \\
\cline { 3 - 4 } & & \multicolumn{1}{l}{ Batch } & Recovery $(\%)$ & & \\
\hline Water 1 & 0.97 & $0.90 \pm 0.02$ & $92.3 \pm 0.03$ & -7.2 & 0.05 \\
& 1.46 & $1.34 \pm 0.01$ & $91.8 \pm 0.01$ & -8.2 & \\
& 2.42 & $2.27 \pm 0.08$ & $93.8 \pm 0.03$ & -6.2 & \\
Water 2 & 3.85 & $3.53 \pm 0.08$ & $91.6 \pm 0.02$ & -8.3 & \\
& 0.97 & $0.97 \pm 0.00$ & $99.4 \pm 0.00$ & 0.0 & 0.24 \\
& 1.46 & $1.43 \pm 0.01$ & $98.4 \pm 0.01$ & -2.1 & \\
& 2.42 & $2.37 \pm 0.04$ & $97.9 \pm 0.02$ & -2.1 & \\
Water 3 & 3.85 & $3.61 \pm 0.02$ & $93.6 \pm 0.00$ & -6.2 & \\
& 0.97 & $0.89 \pm 0.01$ & $91.0 \pm 0.01$ & -8.2 & 0.09 \\
& 1.46 & $1.35 \pm 0.03$ & $93.0 \pm 0.02$ & -7.5 & \\
& 2.42 & $2.11 \pm 0.04$ & $87.1 \pm 0.01$ & -12.8 & \\
Water 4 & 3.85 & $3.32 \pm 0.08$ & $86.2 \pm 0.02$ & -13.8 & \\
& 0.97 & $0.97 \pm 0.01$ & $99.5 \pm 0.01$ & 0.0 & 0.77 \\
& 1.46 & $1.47 \pm 0.02$ & $100.8 \pm 0.01$ & 0.7 & \\
& 2.42 & $2.44 \pm 0.01$ & $100.7 \pm 0.00$ & 0.8 & \\
& 3.85 & $3.84 \pm 0.03$ & $99.6 \pm 0.01$ & -0.3 & \\
Water 5 & 0.97 & $0.96 \pm 0.04$ & $98.4 \pm 0.04$ & -1.0 & 0.19 \\
& 1.46 & $1.41 \pm 0.03$ & $96.8 \pm 0.02$ & -3.4 & \\
& 2.42 & $2.34 \pm 0.01$ & $96.8 \pm 0.00$ & -3.3 & \\
& 3.85 & $3.56 \pm 0.05$ & $92.3 \pm 0.01$ & -7.5 & \\
Water 6 & 0.97 & $1.06 \pm 0.00$ & $100.9 \pm 0.00$ & 9.3 & 0.67 \\
& 1.46 & $1.53 \pm 0.02$ & $104.8 \pm 0.01$ & 4.8 & \\
& 2.42 & $2.42 \pm 0.06$ & $100.0 \pm 0.02$ & 0.0 & \\
& 3.85 & $3.51 \pm 0.04$ & $91.1 \pm 0.01$ & -8.8 & \\
\hline
\end{tabular}

$*$ t critical $=3.18$
Table 4

Potentiomeric determination of TMP in aquaculture water using VPY/MIP based membrane sensor.

\begin{tabular}{|c|c|c|c|c|c|}
\hline \multirow[t]{2}{*}{ Sample } & \multirow{2}{*}{$\begin{array}{l}\text { Concentration } \\
\text { TMP (mg/L) }\end{array}$} & \multicolumn{2}{|l|}{ Found $(\mathrm{mg} / \mathrm{L})$} & \multirow{2}{*}{$\begin{array}{l}\text { ER }(\%) \\
(n=4)\end{array}$} & \multirow[t]{2}{*}{$p$ tailed $^{*}$} \\
\hline & & Batch $(n=4)$ & $\begin{array}{l}\text { Recovery (\%) } \\
(\mathrm{n}=4)\end{array}$ & & \\
\hline \multirow[t]{4}{*}{ Water 1} & 0.97 & $0.90 \pm 0.01$ & $92.4 \pm 0.01$ & -7.2 & 0.04 \\
\hline & 1.46 & $1.29 \pm 0.01$ & $88.4 \pm 0.00$ & -11.6 & \\
\hline & 2.42 & $2.15 \pm 0.01$ & $88.6 \pm 0.01$ & -11.2 & \\
\hline & 3.85 & $3.47 \pm 0.03$ & $90.0 \pm 0.01$ & -9.9 & \\
\hline \multirow[t]{4}{*}{ Water 2} & 0.97 & $0.94 \pm 0.06$ & $97.0 \pm 0.06$ & -3.1 & 0.08 \\
\hline & 1.46 & $1.38 \pm 0.04$ & $94.7 \pm 0.03$ & -5.5 & \\
\hline & 2.42 & $2.26 \pm 0.05$ & $93.2 \pm 0.02$ & -6.6 & \\
\hline & 3.85 & $3.60 \pm 0.08$ & $93.3 \pm 0.02$ & -6.5 & \\
\hline \multirow[t]{4}{*}{ Water 3} & 0.97 & $0.95 \pm 0.03$ & $97.2 \pm 0.03$ & -2.1 & 0.11 \\
\hline & 1.46 & $1.37 \pm 0.04$ & $93.7 \pm 0.03$ & -6.2 & \\
\hline & 2.42 & $2.11 \pm 0.04$ & $87.3 \pm 0.02$ & -12.8 & \\
\hline & 3.85 & $3.73 \pm 0.08$ & $96.8 \pm 0.02$ & -3.1 & \\
\hline \multirow[t]{4}{*}{ Water 4} & 0.97 & $0.90 \pm 0.02$ & $92.1 \pm 0.02$ & -7.2 & 0.01 \\
\hline & 1.46 & $1.36 \pm 0.03$ & $93.3 \pm 0.02$ & -6.8 & \\
\hline & 2.42 & $2.30 \pm 0.08$ & $95.1 \pm 0.03$ & -5.0 & \\
\hline & 3.85 & $3.68 \pm 0.16$ & $95.5 \pm 0.04$ & -4.4 & \\
\hline \multirow[t]{4}{*}{ Water 5} & 0.97 & $0.93 \pm 0.01$ & $95.7 \pm 0.01$ & -4.1 & 0.12 \\
\hline & 1.46 & $1.30 \pm 0.01$ & $89.3 \pm 0.01$ & -11.0 & \\
\hline & 2.42 & $2.19 \pm 0.03$ & $90.3 \pm 0.01$ & -9.5 & \\
\hline & 3.85 & $3.27 \pm 0.02$ & $84.9 \pm 0.01$ & -15.1 & \\
\hline \multirow[t]{4}{*}{ Water 6} & 0.97 & $0.88 \pm 0.01$ & $90.2 \pm 0.01$ & -9.3 & 0.17 \\
\hline & 1.46 & $1.42 \pm 0.00$ & $97.2 \pm 0.00$ & -2.7 & \\
\hline & 2.42 & $2.16 \pm 0.02$ & $89.4 \pm 0.01$ & -10.7 & \\
\hline & 3.85 & $3.11 \pm 0.06$ & $80.6 \pm 0.01$ & -19.2 & \\
\hline
\end{tabular}

$*$ t critical $=3.18$

methods are considerably lower than the potentiometric ones, lying within $3.4 \times 10^{-12}$ to $2.6 \times 10^{-8} \mathrm{~mol} / \mathrm{L}$, pointing out that the proposed method is particularly suitable for screening assays carried out in analytical laboratories or in point-of-contamination. There are no legal levels addressed to TMP in water, but it is quite reasonable to apply the developed method to control TMP levels in the several tanks of the fish farm, when and after this drug is given to the fish.

Considering its routine application, the main advantages arise from the composition and quantity of emitted effluents, with small concern in terms of environmental issues.

\section{Acknowledgements}

The authors acknowledge the financial support from FCT, Fundação para a Ciência e Tecnologia/FEDER by means of project PTDC/AGRAAM/68359/2006.

\section{References}

[1] R.L. Naylor, S.L. Williams, D.R. Strong, Ecology - aquaculture - a gateway for exotic species, Science 294 (2001) 1655-1656.

[2] F.C. Cabello, Heavy use of prophylactic antibiotics in aquaculture: a growing problem for human and animal health and for the environment, Env. Microb 8 (2006) 1137-1144.

[3] C.G. Daughton, T.A. Ternes, Pharmaceuticals and personal care products in the environment: agents of subtle change? Env. Health Persp. 107 (1999) 907-938.

[4] C.S. McArdell, E. Molnar, M.J.F. Suter, W. Giger, Occurrence and fate of macrolide antibiotics in wastewater treatment plants and in the Glatt Valley Watershed, Switzerland, Env. Sci. Tech. 37 (2003) 5479-5486.

[5] M. Ferdig, A. Kaleta, T.D.T. Vo, W. Buchberger, Improved capillary electrophoretic separation of nine (fluoro)quinolones with fluorescence detection for biological and environmental samples, J. Chromatogr. A 1047 (2004) 305-311.

[6] E.M. Golet, A.C. Alder, A. Hartmann, T.A. Ternes, W. Giger, Trace determination of fluoroquinolone antibacterial agents in solid-phase extraction urban wastewater by and liquid chromatography with fluorescence detection, Anal. Chem. 73 (2001) 3632-3638.

[7] Council Regulation (EEC) 2377/90 of 26 June 1990. Consolidated with previous amendments and published by 19 November 2005.

[8] R. Lindberg, P.A. Jarnheimer, B. Olsen, M. Johansson, M. Tysklind, Determination of antibiotic substances in hospital sewage water using solid phase extraction and liquid chromatography/mass spectrometry and group analogue internal standards, Chemosphere 57 (2004) 1479-1488. 
[9] M. Gros, M. Petrovic, D. Barcelo, Development of a multi-residue analytical methodology based on liquid chromatography-tandem mass spectrometry (LCMS/MS) for screening and trace level determination of pharmaceuticals in surface and wastewaters, Talanta 70 (2006) 678-690.

[10] R.N. Rao, N. Venkateswarlu, R. Narsimha, Determination of antibiotics in aquatic environment by solid-phase extraction followed by liquid chromatographyelectrospray ionization mass spectrometry, J. Chromatogr. A 1187 (2008) 151-164

[11] M.J. Hilton, K.V. Thomas, Determination of selected human pharmaceutical compounds in effluent and surface water samples by high-performance liquid chromatography-electrospray tandem mass spectrometry, J. Chromatogr. A 1015 (2003) 129-141.

[12] V.V. Cosofret, R.P. Buck, Recent advances in pharmaceutical analysis with potentiometric membrane sensors, Crit. Rev. Anal. Chem. 24 (1993) 1-58.

[13] S. Amemiya, Chapter 7. Potentiometric Ion-Selective Electrodes, in: C.G. Zoski (Ed.), Handbook of Electochemistry, Elsevier, 2007, pp. 261-294.

[14] G. Wulff, Enzyme-like catalysis by molecularly imprinted polymers, Chem. Rev. 102 (2002) 1-27.

[15] G. Vlatakis, L.I. Andersson, R. Muller, K. Mosbach, Drug assay using antibody mimics made by molecular imprinting, Nature 361 (1993) 645-647.

[16] K. Hosoya, Y. Shirasu, K. Kimata, N. Tanaka, Molecularly imprinted chiral stationary phase prepared with racemic template, Anal. Chem. 70 (1998) 943-945.

[17] B. Sellergren, Imprinted dispersion polymers - a new class of easily accessible affinity stationary phases, J. Chromatogr. A 673 (1994) 133-141.

[18] P. Spegel, L. Schweitz, S. Nilsson, Molecularly imprinted polymers in capillary electrochromatography: recent developments and future trends, Electrophoresis 24 (2003) 3892-3899.

[19] N. Lavignac, C.J. Allender, K.R. Brain, Current status of molecularly imprinted polymers as alternatives to antibodies in sorbent assays, Anal. Chim. Acta 510 (2004) 139-145.

[20] K. Nilsson, J. Lindell, O. Norrlow, B. Sellergren, Imprinted polymers as antibody mimetics and new affinity gels for selective separations in capillary electrophoresis, J. Chromatogr. A 680 (1994) 57-61.

[21] L. Ye, K. Mosbach, Molecularly imprinted microspheres as antibody binding mimics, Reac. Func. Polym. 48 (2001) 149-157.

[22] P. Manesiotis, A.J. Hall, J. Courtois, K. Irgum, B. Sellergren, An artificial riboflavin receptor prepared by a template analogue imprinting strategy, Ang. Chem. Intern. Ed. 44 (2005) 3902-3906.
[23] S. Marx, A. Zaltsman, I. Turyan, D. Mandler, Parathion sensor based on molecularly imprinted sol-gel films, Anal. Chem. 76 (2004) 120-126.

[24] K. Hirayama, Y. Sakai, K. Kameoka, K. Noda, R. Naganawa, Preparation of a sensor device with specific recognition sites for acetaldehyde by molecular imprinting technique, Sens. Act. B Chem. 86 (2002) 20-25.

[25] D. Kriz, O. Ramstrom, K. Mosbach, Molecular imprinting - new possibilities for sensor technology, Anal. Chem. 69 (1997) A345-A349.

[26] L.I. Andersson, Molecular imprinting for drug bioanalysis: a review on the application of imprinted polymers to solid-phase extraction and binding assay, J. Chromatogr. B Biomed. 739 (2000) 163-173.

[27] F. Lanza, B. Sellergren, The application of molecular imprinting technology to solid phase extraction, Chromatographia 53 (2001) 599-611.

[28] M.M. Ariffin, E.I. Miller, P.A.G. Cormack, R.A. Anderson, Molecularly imprinted solid-phase extraction of diazepam and its metabolites from hair samples, Anal Chem. 79 (2007) 256-262.

[29] A.H. Kamel, F.T.C. Moreira, S.A.A. Almeida, M.G.F. Sales, Novel potentiometric sensors of molecular imprinted polymers for specific binding of chlormequat, Electroanalysis 20 (2008) 194-202.

[30] F.L. Dickert, O. Hayden, Molecular imprinting in chemical sensing, Trac Trends. Anal. Chem. 18 (1999) 192-199.

[31] F. Faridbod, M.R. Ganjali, R. Dinarvand, P. Norouzi, Developments in the field of conducting and non-conducting polymer based potentiometric membrane sensors for ions over the past decade, Sensors 8 (2008) 2331-2412.

[32] IUPAC, Analytical chemistry division commission on analytical nomenclature, Pure Appl. Chem. 72 (2000) 1851-2082.

[33] M. Telting-Diaz, E. Bakker, Effect of lipophilic ion-exchanger leaching on the detection limit of carrier-based ion-selective electrodes, Anal. Chem. 73 (2001) 5582-5589.

[34] S. Babic, D. Asperger, D. Mutavdzic, A.J.M. Horvat, M. Kastelan-Macan, Determination of sulfonamides and trimethoprim in spiked water samples by solid-phase extraction and thin-layer chromatography, Jpc J. Plan. Chromatogr. Mod. Tlc 18 (2006) 423-426.

[35] Y. Umezawa, P. Buhlmann, K. Umezawa, K. Tohda, S. Amemiya, Potentiometric selectivity coefficients of ion-selective electrodes Part I. Inorganic cations (technical report), Pure Appl. Chem. 72 (2000) 1851-2082. 